Discussion Paper No. 758

\title{
INCOME DISTRIBUTION AND \\ MACROECONOMICS REVISITED: \\ THE ROLE OF FERTILITY ADJUSTMENT
}

\author{
Masao Nakagawa \\ Yoshiaki Sugimoto
}

November 2009

The Institute of Social and Economic Research

Osaka University

6-1 Mihogaoka, Ibaraki, Osaka 567-0047, Japan 


\title{
Income Distribution and Macroeconomics Revisited: The Role of Fertility Adjustment*
}

\author{
Masao Nakagawa ${ }^{\mathrm{a}}$ and Yoshiaki Sugimoto ${ }^{\mathrm{b}, \dagger}$

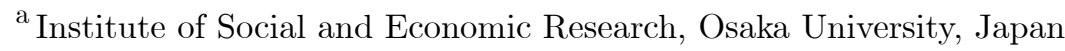 \\ ${ }^{\mathrm{b}}$ Faculty of Economics, Kagawa University, Japan
}

November 7, 2009

\begin{abstract}
This paper develops a theory in which households prepare for future education by adjusting the number of children they intend to raise. Income inequality lowers output per worker only if the inequality is attributed in some part to unexpected disturbances after childbirth.
\end{abstract}

Keywords: Fertility; Lock-in effect; Inequality; Education.

JEL Classification: D10; J13; J24; O15.

\section{Introduction}

This paper reconsiders the significance of income distribution in macroeconomics, a topic that has attracted the attention of economists since the 1990s. They have explored various mechanisms to explain the negative aspects of inequality. In particular, Galor and Zeira (1993) theoretically argued that, in developed economies with imperfect capital markets, inequality retards human capital accumulation and economic growth. ${ }^{1}$

While the subsequent studies in this line of research incorporate the fertility decisions of households (cf. Kremer and Chen, 1999; de la Croix and Doepke, 2003), one important aspect of child rearing has been omitted. As formulated by Becker and Lewis (1973), parents face a quantityquality trade-off of their children. This implies the possibility that, in developed economies, where

\footnotetext{
${ }^{*}$ The authors are grateful to seminar participants at Kagawa and Keio Universities for their helpful comments.

${ }^{\dagger}$ Corresponding author. 2-1 Saiwai-cho, Takamatsu 760-8523, Japan. Tel.: +81 878321836 ; fax: +81 87832 1820. E-mail address: sugimoto@ec.kagawa-u.ac.jp (Y. Sugimoto).

${ }^{1}$ Other theories using the capital-market imperfection approach include those of Banerjee and Newman (1993), Aghion and Bolton (1997), Moav (2002), Mookherjee and Ray (2003), and Galor and Moav (2004).
} 
skill acquisition is advantageous, households in various income classes adjust the number of children they raise in order to ensure that the children can attain certain education levels. This fertility adjustment moderates the link between income inequality and skill differentials.

Based on this motivation, the present research develops a simple theory that allows for unexpected, idiosyncratic income shocks between childbirth and education decisions. Since childbirth is an irreversible investment in the quantity of children (cf. Fraser, 2001; Doepke and Zilibotti, 2005), locked-in fertility hinders education investment by households that are unexpectedly poor. In this situation, a mean-preserving spread of such shocks may increase the proportion of credit-constrained children, leading to lower average human capital, output per worker, and average fertility.

\section{The Model}

The economy has a small, open, overlapping-generations structure and operates over an infinite time horizon $t \geq 0 .^{2}$

\subsection{Production}

In perfectly competitive environments, producers generate a single homogeneous good by using physical and human capital. Only physical capital is mobile across economic borders. Production technology is represented as a function $F$ that fulfills all of the neoclassical properties. Then, the aggregate quantity of final output produced in period $t$, denoted as $Y_{t}$, is

$$
Y_{t}=F\left(K_{t}, H_{t}\right)=F\left(K_{t} / H_{t}, 1\right) H_{t} \equiv f\left(k_{t}\right) H_{t}
$$

where $K_{t}$ and $H_{t}$ denote the aggregate levels of physical and human capital, respectively, used in period $t$. The price of the final good is normalized to unity, and physical capital is assumed not to depreciate. Each competitive producer maximizes its own profit by taking factor prices as given. Hence, $K_{t}$ and $H_{t}$ maximize $Y_{t}-r K_{t}-w_{t} H_{t}$, where $r>0$ denotes the stationary interest rate in the global capital markets, and $w_{t}$ is the wage rate per unit of human capital (effective labor) in period $t$. Accordingly,

$$
r=f^{\prime}\left(k_{t}\right) ; \quad w_{t}=f\left(k_{t}\right)-f^{\prime}\left(k_{t}\right) k_{t} \equiv w,
$$

where $k_{t}=f^{\prime-1}(r) \equiv k>0$.

\footnotetext{
${ }^{2}$ The model is an extension of Galor and Weil (2000), who explore the mechanism underlying the demographic transition in the long-term growth process.
} 


\subsection{Households}

A new generation is born at the beginning of each period and lives for three periods. Consider the life of individual $i \in\left[0, N_{t}\right]$ of generation $t$ (born in period $t-1$ ), where $N_{t}$ is the population size of generation $t$. In the first period (childhood), the individual consumes $\left(\delta+e_{t-1}^{p(i)}\right)$ units of effective labor of her parent $p(i) \in\left[0, N_{t-1}\right]$, where $\delta>0$ and $e_{t-1}^{p(i)}>0$ denote the fixed cost and the education cost, respectively. ${ }^{3}$ In the second period (adulthood/parenthood), the individual acquires $h_{t}^{i}$ units of effective labor, which is a function of not only $e_{t-1}^{p(i)}$ but also $a_{t}^{i}$, an exogenous, unexpected, idiosyncratic shock on abilities, health, and so on. More specifically,

$$
h_{t}^{i}=a_{t}^{i} h\left(e_{t-1}^{p(i)}\right)
$$

where $h$ is a continuous function such that $h^{\prime}(e)>0$ and $h^{\prime \prime}(e)<0 \forall e>0$ and $h(0) \geq 0$, $\lim _{e \rightarrow 0} h^{\prime}(e)=\infty$, and $\lim _{e \rightarrow \infty} h^{\prime}(e)=0$. The acquired labor is allocated between child rearing and working. The adult individual raises $n_{t}^{i}$ units of children by spending $\left(\delta+e_{t}^{i}\right)$ units of effective labor per child. Supplying the remaining labor to producers brings her wage incomes, that are saved for consumption during the retirement period (elderhood), $c_{t+1}^{i}$. It follows that

$$
c_{t+1}^{i}=R w\left[h_{t}^{i}-\left(\delta+e_{t}^{i}\right) n_{t}^{i}\right]
$$

where $R \equiv 1+r$. The preferences of this individual are described by

$$
u_{t}^{i}=(1-\alpha) \ln c_{t+1}^{i}+\alpha \ln \left[n_{t}^{i} h\left(e_{t}^{i}\right)\right]
$$

where $\alpha \in(0,1)$ and $h\left(e_{t}^{i}\right)$ is the deterministic component of human capital of their children.

\subsection{Optimization}

In period $t$, the unexpected shock $a_{t}^{i}$ happens to parent $i$ between two events: childbirth and education investment. The parent decides the number of children by assuming her skill level to be $h_{t}^{i}=h\left(e_{t-1}^{p(i)}\right)$. In light of Eqs. (3) and (4), the optimal choice in this circumstance is given by

$$
\left\{n_{t}^{i}, \bar{e}\right\}=\arg \max \left\{(1-\alpha) \ln \left[h\left(e_{t-1}^{p(i)}\right)-(\delta+\bar{e}) n_{t}^{i}\right]+\alpha \ln \left[n_{t}^{i} h(\bar{e})\right]\right\}
$$

\footnotetext{
${ }^{3}$ The case in which $e_{t-1}^{p(i)}=0$ is excluded here, because our focus is on developed economies, where education investment prevails.
} 
where $\bar{e}$ denotes the ex-ante optimal level of education. The two first-order conditions yield ${ }^{4}$

$$
n_{t}^{i}=\frac{\alpha}{\delta+\bar{e}} h\left(e_{t-1}^{p(i)}\right)
$$

This fertility choice is assumed to be irreversible.

Then, by the time an education decision is made, the parent observes $a_{t}^{i}$ and thus $h_{t}^{i}=a_{t}^{i} h\left(e_{t-1}^{p(i)}\right)$. As follows from Eqs. (3), (4), and (5), the ex-post optimal (and actually chosen) level of education is

$$
e_{t}^{i}=\arg \max \left\{(1-\alpha) \ln \left[a_{t}^{i}-a^{\min }\left(1+e_{t}^{i} / \delta\right)\right]+\alpha \ln h\left(e_{t}^{i}\right)\right\}
$$

where it is assumed that $a_{t}^{i}>a^{\min } \equiv \alpha \delta /(\delta+\bar{e}) \in(0,1)$ to ensure $c_{t+1}^{i}>0$. This assumption excludes the possibility that parents unexpectedly have too many children to raise and therefore cannot invest in education. Then, the first-order condition is

$$
a_{t}^{i}=\frac{a^{\min }}{\delta}\left[\delta+e_{t}^{i}+\frac{1-\alpha}{\alpha} \frac{h\left(e_{t}^{i}\right)}{h^{\prime}\left(e_{t}^{i}\right)}\right] \equiv D\left(e_{t}^{i}\right)
$$

where $D^{\prime}\left(e_{t}^{i}\right)>0 \forall e_{t}^{i}>0, D(\bar{e})=1, \lim _{e_{t}^{i} \rightarrow 0} D\left(e_{t}^{i}\right)=a^{\min }$, and $\lim _{e_{t}^{i} \rightarrow \infty} D\left(e_{t}^{i}\right)=\infty$. These properties of $D$ ensure that for any $a_{t}^{i}>a^{\text {min }}$, there exists a unique value $e_{t}^{i}>0$ satisfying Eq. (7). Then, applying the Implicit Function Theorem, there exists a single-valued function such that

$$
e_{t}^{i}=e\left(a_{t}^{i}\right)>0
$$

where $e^{\prime}\left(a_{t}^{i}\right)>0 \forall a_{t}^{i}>a^{\min }, e(1)=\bar{e}$, and $\lim _{a_{t}^{i} \rightarrow a^{\min }} e\left(a_{t}^{i}\right)=0$. Hence, the determining factor in education investment is $a_{t}^{i}$, which is equal to the ratio of the ex-post level of human capital to the to the ex-ante level of human capital, $h_{t}^{i} / h\left(e_{t-1}^{p(i)}\right)$. The positive relationship of $e_{t}^{i}$ with $a_{t}^{i}$ indicates a downward adjustment of education in response to a negative income shock.

\subsection{Credit Constraint}

In the economy considered herein, no one can take out loans because of some imperfections in capital markets. Let $e^{*}$ be the labor cost of education preferred by a child in the absence of the borrowing constraint. Then,

$$
e^{*}=\arg \max \left[w h\left(e^{*}\right)-R w e^{*}\right]
$$

\footnotetext{
${ }^{4} \bar{e}$ is a positive value such that $Q(\bar{e}) \equiv h^{\prime}(\bar{e})(\delta+\bar{e})-h(\bar{e})=0$. The existence and uniqueness of this solution are ensured by the following results, which are derived from the properties of the function $h: Q^{\prime}(\bar{e})<0 \forall \bar{e}>0$, $\lim _{\bar{e} \rightarrow 0} Q(\bar{e})=\infty$, and $\lim _{\bar{e} \rightarrow \infty} Q(\bar{e})=\lim _{\bar{e} \rightarrow \infty}\left[h^{\prime}(\bar{e}) \bar{e}-h(\bar{e})\right]<0$, where the last inequality holds because, on the interval $(0, \infty)$, the difference in the square brackets is negative (by concavity) and decreasing.
} 
where $w e^{*}$ is the payment to the child's teacher. As a result of the first-order condition $h^{\prime}\left(e^{*}\right)=R$, $e^{*}$ is a positive constant over time, and the corresponding disturbance level is such that $e\left(a^{*}\right)=e^{*}$ and thus $a^{*}>a^{\min .5}$ These results and the properties of $e\left(a_{t}^{i}\right)$ reveal that

$$
e_{t}^{i}=e\left(a_{t}^{i}\right) \begin{cases}<e^{*} & \text { for } a_{t}^{i}<a^{*} \\ \geq e^{*} & \text { for } a_{t}^{i} \geq a^{*}\end{cases}
$$

In the first case above, the education provided by a parent is insufficient for her children - a situation in which the borrowing constraint is binding. In contrast, in the second case, the children would not need further education even without the constraint.

The analysis below is limited to the case in which the child is not credit-constrained if her parent receives the average income shock. That is, in view of (10),

$$
a^{*} \leq 1
$$

This condition is met if the borrowing cost is sufficiently large, noting that $h^{\prime}\left(e\left(a^{*}\right)\right)=R$.

In light of the restriction $a_{t}^{i}>a^{\text {min }}$ imposed above, it is analytically convenient to consider that $\ln \left(a_{t}^{i}-a^{\min }\right)$ is normally distributed with mean $\mu_{t}$ and variance $\sigma_{t}$. Then, the cumulative distribution function (cdf) of $a_{t}^{i}$ is

$$
G_{t}(a) \equiv \operatorname{Pr}\left(a_{t}^{i}<a\right)=\Phi\left(\frac{\ln \left(a-a^{\min }\right)-\mu_{t}}{\sigma_{t}}\right)
$$

where $a>a^{\text {min }}$ and $\Phi$ denotes the cdf of the standard normal distribution. ${ }^{6}$ This specification implies that all members within each generation are exposed to the same risk, and that the shocks are independent of each other across individuals and time (i.e., $a_{t}^{i} \perp a_{\tau}^{j}$ for any $i \in\left[0, N_{t}\right], j \in\left[0, N_{\tau}\right]$, and $t, \tau \geq 0)$. Now suppose that

$$
\mu_{t}+\sigma_{t}^{2} / 2=\ln \left(1-a^{\min }\right)
$$

so that the mean and the variance of $a_{t}^{i}$ are $E\left(a_{t}^{i}\right)=1$ and $\operatorname{var}\left(a_{t}^{i}\right)=\left(1-a^{\min }\right)^{2}\left(\exp \sigma_{t}^{2}-1\right)$, respectively. Thus, on average, no disturbance $\left(a_{t}^{i}=1\right)$ occurs, and an increase in $\sigma_{t}$ creates a mean-preserving spread of $a_{t}^{i}$.

\footnotetext{
${ }^{5}$ The existence and the uniqueness of $e^{*}$ and $a^{*}$ are guaranteed by the properties of $h\left(e_{t}^{i}\right)$ and $e\left(a_{t}^{i}\right)$ in Eqs. (2) and (8), respectively. In Eq. (9), the future income shock is unexpected and therefore is not taken into account.

${ }^{6}$ The last equality follows from the fact that $\operatorname{Pr}\left(\ln \left(a_{t}^{i}-a^{\mathrm{min}}\right)<\ln \left(a-a^{\mathrm{min}}\right)\right)=\operatorname{Pr}\left(a_{t}^{i}<a\right)$.
} 
Proposition 1 Under Eqs. $(A 1)$ and $(A 2)$, an increase in $\sigma_{t}$ increases the fraction of children who are credit-constrained (i.e., $\left.e_{t}^{i}<e^{*}\right)$.

Proof. Given the two assumptions, Eq. (11) reveals that an increase in $\sigma_{t}$ increases $G_{t}\left(a^{*}\right)$, thereby increasing the fraction of adult individuals with $a_{t}^{i}<a^{*}$. Hence, the proposition follows from Eq. (10).

The proposition results from the irreversibility of the fertility decision. Once children are born, parents have to raise them even if the parental incomes become unexpectedly low. Thus, a meanpreserving spread of the unexpected shocks, which occur after childbirth, prevents more households from providing the education level preferred by their children.

\subsection{Aggregate Variables}

Recalling that $a_{t+1}^{i}$ has a mean of unity and is independent of the past shocks, the average level of human capital of the working population in period $t+1$ is

$$
E\left(h_{t+1}^{i}\right)=E\left[h\left(e_{t}^{p(i)}\right)\right]=\int_{a^{\min }}^{\infty} h(e(a)) d G_{t}(a) .
$$

In addition, $E\left(h_{0}^{i}\right)$ is obtained from a historically determined distribution of ex-ante human capital in period 0. Then, Eq. (1) shows that output per worker in period $t$ is expressed as $y_{t}=f(k) H_{t} / N_{t}$, where, noting the private cost of child rearing in Eq. (6), we have

$$
\frac{H_{t}}{N_{t}}=E\left(h_{t}^{i}\right)\left\{1-a^{\min }\left[1+\frac{1}{\delta} \int_{a^{\min }}^{\infty} e(a) d G_{t}(a)\right]\right\}
$$

Let $n_{t}$ be the average number of children per adult individual in period $t$. In view of Eq. (5), the evolution of the working population is

$$
N_{t+1}=n_{t} N_{t}=\frac{\alpha}{\delta+\bar{e}} N_{t} E\left(h_{t}^{i}\right)
$$

where the initial level $N_{0}$ is given historically. Thus, a lower level of average human capital discourages fertility, leading to slower growth of the working population.

The following analysis examines the case in which $e^{\prime \prime}\left(a_{t}^{i}\right) \leq 0$ for any $a_{t}^{i}>a^{\text {min }}$. Namely, in response to a marginal change in the unexpected shock, richer parents adjust their education 


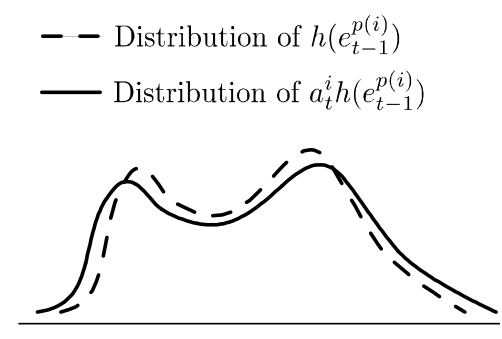

(a)

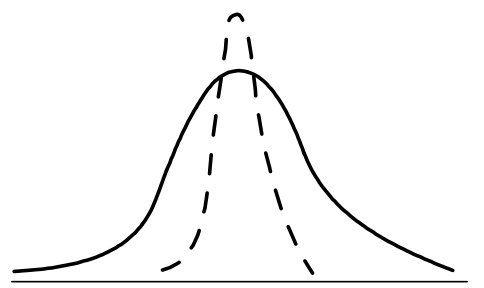

(b)

Figure 1. Distributions of Human Capital

investment less sensitively. This case occurs if the function $D$ in Eq. (7) satisfies $^{7}$

$$
D^{\prime \prime}\left(e_{t}^{i}\right) \geq 0 \quad \forall e_{t}^{i}>0
$$

Proposition 2 Under Eqs. (A2) and (A3), an increase in $\sigma_{t}$ reduces average human capital $E\left(h_{t+1}^{i}\right)$, output per worker $y_{t+1}$, and the working population $N_{t+\tau}$, where $\tau \geq 2$.

Proof. Since Eqs. (2) and (A3) reveal that $h(e(a))$ in Eq. (12) is strictly concave with respect to $a$, an increase in $\sigma_{t}$ decreases $E\left(h_{t+1}^{i}\right)$. Therefore, the other results follow from Eqs. (13) and (14).

As stated above, the negative effect of a mean-preserving spread, which widens the income distribution, results from the concave relationship between the income shock on a parent, $a_{t}^{i}$, and the skill level of each of her children. Among the determinants of parental incomes, the key factor here is the unexpected factor $a_{t}^{i}$, rather than the predetermined factor $e_{t-1}^{p(i)}$. If $\sigma_{t}$ was small, the distribution of ex-post human capital in period $t, a_{t}^{i} h\left(e_{t-1}^{p(i)}\right)$, would largely reflect the dispersion of the latter. Then the number of children chosen in advance would, as mostly expected, be small enough to allow the parents to provide the education preferred by their children (i.e., $\left.e_{t}^{i} \geq e^{*}\right)$. This fertility adjustment moderates the correlation of skills between parents and their children, thereby mitigating the negative impact of inequality on future output.

The importance of distinguishing these two factors is shown by Figure 1. While the distribution of $a_{t}^{i} h\left(e_{t-1}^{p(i)}\right)$ in panel (a) has a higher degree of inequality than that in panel (b), the former reflects in larger part the variation of $e_{t-1}^{p(i)}$. According to Proposition 2, such higher inequality leads to higher output per worker - a situation that was overlooked in the previous studies (cf. Footnote 1).

\footnotetext{
${ }^{7}$ The sign of $D^{\prime \prime}\left(e_{t}^{i}\right)$, including the third derivative $h^{\prime \prime \prime}\left(e_{t}^{i}\right)$, is generally ambiguous. For example, $D^{\prime \prime}\left(e_{t}^{i}\right)>0$ if $h^{\prime \prime \prime}\left(e_{t}^{i}\right)<0$, and $D^{\prime \prime}\left(e_{t}^{i}\right)=0$ if $h\left(e_{t}^{i}\right)=\left(e_{t}^{i}\right)^{\phi}$, where $\phi \in(0,1)$. As clarified later herein, Eq. (A2) is unnecessary as long as $h(e(a))$ is strictly concave with respect to $a$.
} 


\section{Concluding Remarks}

This article has demonstrated that under some conditions, the contribution of unexpected factors in income distribution, rather than the degree of inequality itself, is a key determinant of macroeconomic performance. The focus of the present research was on the irreversible fertility decisions that are made prior to education investment. One may interpret locked-in fertility as an implicit assumption in the previous literature on inequality, education, and growth. Our result indicates that mitigating the uncertainty of parental incomes will raise output per worker in the next generation. In the presence of credit constraints, one useful policy would be to enrich public insurance systems for health and unemployment.

While the central thesis of the present research is intuitive, the developed theory builds on a number of simplifying assumptions. In more general environments, predetermined as well as unexpected factors of income distribution would be relevant to education investment. The relative importance of these factors should be empirically investigated in the future.

\section{References}

Aghion, Philippe and Patric Bolton (1997), "A Trickle-Down Theory of Growth and Development with Debt Overhang," Review of Economic Studies, Vol. 64, No. 2, pp. 151-72.

Banerjee, Abhijit V. and Andrew Newman (1993), "Occupational Choice and the Process of Development," Journal of Political Economy, Vol. 101, No. 2, pp. 274-298.

Becker, Gary S. and H. Gregg Lewis (1973), "On the Interaction between the Quantity and Quality of Children," Journal of Political Economy, Vol. 81, No. 2, pp. S279-S288, March-April.

de la Croix, David and Matthias Doepke (2003), "Inequality and Growth: Why Differential Fertility Matters," American Economic Review, Vol. 93, No. 4, pp. 1091-1113, September.

Doepke, Matthias and Fabrizio Zilibotti (2005), "The Macroeconomics of Child Labor Regulation," American Economic Review, Vol. 95, No. 5, pp. 1492-1524, December.

Fraser, Clive D. (2001), "Income Risk, the Tax-benefit System and the Demand for Children," Economica, Vol. 68, No. 269, pp. 105-125, February.

Galor, Oded and Omer Moav (2004), "From Physical to Human Capital Accumulation: Inequality and the Process of Development," Review of Economic Studies, Vol. 71, No. 4, pp. 1001-1026, October.

Galor, Oded and David N. Weil (2000), "Population, Technology, and Growth: From Malthusian Stagnation to the Demographic Transition and Beyond," American Economic Review, Vol. 90, No. 4, pp. 806-828, September.

Galor, Oded and Joseph Zeira (1993), "Income Distribution and Macroeconomics," Review of Economic Studies, Vol. 60, No. 1, pp. 35-52, January.

Kremer, Michael and Daniel Chen (1999), "Income-Distribution Dynamics with Endogenous Fertility," American Economic Review: Papers and Proceedings, Vol. 89, No. 2, pp. 155-160, May.

Moav, Omer (2002), "Income Distribution and Macroeconomics: The Persistence of Inequality in a Convex Technology Framework," Economic Letters, Vol. 75, No. 2, pp. 187-92, April.

Mookherjee, Dilip and Debraj Ray (2003), "Persistent Inequality," Review of Economic Studies, Vol. 70, No. 2, pp. 369-393, April. 